\title{
RESTLESS LEGS SYNDROME
}

\section{Study of prevalence among medical school faculty members}

\author{
Fábio Maraschin Haggstram?', Andre Vicente Bigolin', Aline Sponchiado Assoni ${ }^{2}$, Cristiane Mezzomo $^{2}$, \\ Isabela Wasum dos Santos², Mariele Ribeiro Correa², Tatiana Linhares², Claudia Franzoi Fam ${ }^{3}$
}

\begin{abstract}
The aim of this study was to assess the prevalence of idiopathic restless legs syndrome (RLS) and its correlations in a sample of Medical School faculty members. A transversal study was conducted at a Medical School in the south of Brazil included 78 faculty members. The subjects answered to a structured questionnaire specific to RLS diagnosis and the Epworth and the Stanford scales to measure daytime sleepiness. Severity of the disease was also evaluated. The variables were analyzed to statistical significance. RLS was diagnosed in $10.25 \%$ of the subjects evaluated and most were women (62.5\%). The prevalence of daytime sleepiness was significantly greater among the subjects suffering from RLS ( $p=0.04)$. RLS subjects were significantly younger than the group without the syndrome $(p=0.02)$. RLS had a considerable prevalence in the sample studied. Daytime sleepiness and young age showed an important correlation to this syndrome, as other potential factors were not confirmed.
\end{abstract}

KEY WORDS: restless leg syndrome, prevalence, idiopathic, daytime sleepness.

\begin{abstract}
Sindrome das pernas inquietas: estudo de prevalência entre professores do curso de medicina
Resumo - O objetivo deste estudo foi analisar a prevalência da síndrome das pernas inquietas (SPI) e suas implicações clínicas em uma amostra envolvendo docentes de um curso de Medicina. Foi realizado um estudo transversal que envolveu 78 docentes do curso de Medicina de uma Universidade do Sul do Brasil. Os indivíduos avaliados responderam um questionário com perguntas epidemiológicas e de diagnóstico para SPI, assim como escalas de sonolência de Epworth e Stanford. Os portadores de SPI responderam questionário de gravidade. As variáveis foram analisadas quanto à significância estatística. Obtivemos uma prevalência de indivíduos portadores de SPI de 10,25\%, sendo 62,5\% destes do sexo feminino. A existência de sonolência diurna excessiva foi significativamente maior em pacientes portadores da síndrome $(p=0,04)$. Os pacientes portadores de SPI possuíam idade significativamente inferior ao grupo não sindrômico ( $p=0,02)$. A SPI mostrou-se bastante prevalente em nossa amostra. A prevalência de sonolência diurna e menos idade mostrou importante relação com esta síndrome, enquanto outros fatores possivelmente relacionados não foram confirmados.
\end{abstract}

PALAVRAS-CHAVE: síndrome das pernas inquietas, prevalência, idiopática, sonolência diurna.

Restless legs syndrome (RLS) was first described by Thomas Willis in 1685, but only in 1944 Ekbom studied it in more details ${ }^{1}$. Fifty years after its complete description, definition and major criteria to its diagnosis was published by a group entitled International Restless Legs Syndrome Study Group (IRLSSG) ${ }^{2}$. Despite the fact of being long known and of high prevalence in the population, knowledge about RLS still remains very limited among health care professionals $s^{3,4}$.
RLS is diagnosed using the diagnosis criteria of the International RLS study group - IRLSSG - characterized exclusively by subjective sensations of discomfort and paresthesia in limbs, especially in lower limbs, present at rest and decreased by the urge to move the limbs. Although the great the impact it has on the patients' quality of life, it is a clinical condition which neurophysiologic and physiopathology mechanisms have been clearly revealed. In 2001, the National Sleep Foundation found its prevalence

Pneumosono - Centro de Distúrbios do Sono, Porto Alegre RS, Brazil: 'MD, PhD, Pneumologist and specialist in Sleep Medicine, ULBRA Medical School Professor; ${ }^{2}$ Medical students at ULBRA Medical School; ${ }^{3}$ Medical student at UFRGS - Federal University of Rio Grande do Sul, Porto Alegre RS, Brazil.

Received 27 January 2009, received in final form 30 June 2009. Accepted 7 July 2009.

Dr. Fábio Maraschin Haggsträm - Rua José de Alencar 181 / $2^{\circ}$ andar (Pneumosono) - 90880-481 Porto Alegre RS - Brasil. E-mail: fabiomaraschin@ hotmail.com 
to be around $13 \%$ of the population, but only $3 \%$ had previously diagnosed the syndrome ${ }^{5,6}$. Many other studies have demonstrated that the highest point of discomfort in lower limbs occurs after midnight, respecting a circadian rhythm. In this manner continuous movements of legs can evocate sleep disturbances, leading to cognitive and functional deficit due to sleep during day time, the last being one of the important characteristics of the syndrome. This symptom can be measured by scales, such as the ones developed by Epworth and Stanford, which are highly helpful in the investigation when there is a clinical suspicion of RLS ${ }^{7,8}$.

Idiopathic form is the most frequent type of the syndrome, but some factors are highly correlated to the incidence of RLS and should be considered in clinical investigations. Clinical conditions such as anemia due to iron deficiency, pregnancy, renal failure, diabetes mellitus, hypothyroidism and Parkinson disease have been described ${ }^{6,9-11}$. The diagnosis of the syndrome is purely clinical and its early recognition is highly recommended, because of the huge impact on patients suffering that can be alleviated by the use of treatment with dopamine agonists.

RLS prevalence among Brazilian medical school faculty members and its correlations were evaluated in this project.

\section{METHOD}

Seventy eight professors at the School of Medicine- ULBRA were included in this transversal study; representing $88 \%$ of all faculty members ( $66,6 \%$ were men). A total of 10 professors did not meet inclusion criteria.

The sample population had to be in the range of 30 and 65 years old and should not meet any of the exclusion criteria, now listed: no wish to participate in the study, history of anemia, chronic renal failure, Parkinson disease, hypothyroidism, diabetes mellitus and history of neoplasia in the past or present time. No blood or other exams were done to confirm or exclude those diseases.

Each subject answered a standardized instrument containing demographic questions and questions concerning RLS. Among the questions, 4 specific questions were used to establish diagnosis based on the criteria created by the IRLSSG:

(a) Do you feel an urge to move your legs, usually accompanied or caused by uncomfortable or unpleasant sensations in the legs?

(b) Do the urge to move or unpleasant sensations begin or worsen during periods of rest or inactivity such as lying or sitting?

(c) Are the urge to move or unpleasant sensations partially or totally relieved by movement, such as walking or stretching, at least as long as the activity continues?

(d) Are the urge to move or unpleasant sensations worse in the evening or night than during the day or only occur in the evening or night?

The possible answers to the previous questions were: "yes", "no" e "I don't know". Only the individuals who answered "yes" to all 4 questions were considered as suffering from RLS.

The RLS-positive subjects were submitted to the IRLSSG severity rating scale ${ }^{12}$. This scale uses 10 items with 5 levels of response, enabling the measurement of all symptoms and their impacts. As a way to highlight the presence of daytime sleepiness two scales were employed: Epworth ${ }^{7}$ and Stanford ${ }^{8}$.

All questionnaires were reviewed by interviewers soon after its application. The variables were analyzed by statistical software SPSS ${ }^{\otimes}$ using the chi-square and t-student test for the qualitative and quantitative variables, respectively. Thus we consider a variable as statistically significant when $p<0.05$.

This study was conducted with approval of the protocol by the Research Ethics Committee of the institution and all participants signed a written informed consent.

The first subject was included in August of 2007 and the last in December of 2007.

\section{RESULTS}

The general characteristics of the sample are shown in Table 1. The prevalence of patients that matched the diagnostic for RLS was $10.25 \%$. Among the subjects with the syndrome most were female $62.5 \%(p=0.08)$.

We administered the IRLSSG severity rating scale to RLS-positive subjects. It revealed an average score of 11 points (that mean a moderate severity). Knowledgement of RLS was found in $80.76 \%$ of the participants.

According to the Epworth scale, the presence of daytime sleepiness showed a mean score of 7.82 points, while $19.23 \%$ had scores indicative of excessive daytime sleepiness (12 points or more). Considereing the Stanford Scale,

Table 1. General characteristics of the sample.

\begin{tabular}{lcc}
\hline Variable & $\mathrm{N}^{\circ}$ & $\%$ \\
\hline Age & 78 & 46.53 years \\
$\quad$ Average & & \\
Sex & 26 & 33.3 \\
$\quad$ Female & 52 & 66.7 \\
$\quad$ Male & & \\
BMI & 69 & 88.5 \\
Non obese & 9 & 11.5 \\
Obese & 78 & 25.2 \\
Average & & \\
Quit smoking & 68 & 87.2 \\
No & 10 & 12.8 \\
Yes & & \\
Smoking & 75 & 96.2 \\
No & 3 & 3.8 \\
Yes & 78 & 100.0 \\
Total &
\end{tabular}

BMI: Body mass index (obtained by dividing body weight in kilograms by the square of height in meters). 


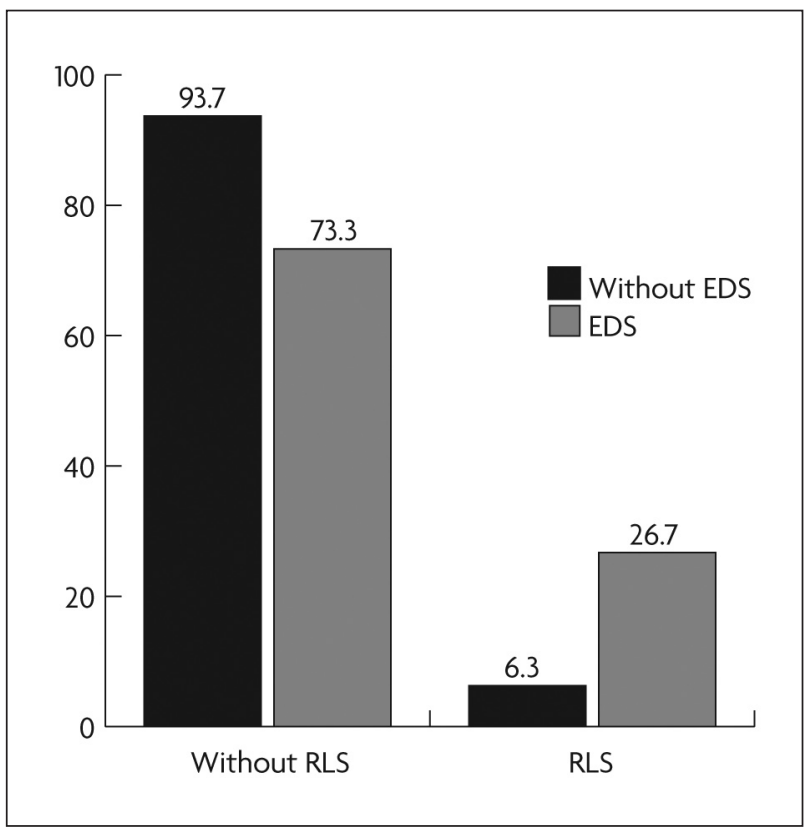

Figure. Prevalence of excessive daytime sleepiness (EDS) in Restless Leg Syndrome patient.

the mean score wes 1.56 points. There was no statistical difference in the mean scores in these questionnaires in the studied groups ( $p=0.11$ Epworth / $p=0.09$ Stanford).

The results of chi-square pointed at the existence of a significant association between the presence of RLS and daytime sleepiness. It is observed that patients presenting daytime sleepiness were more likely to have clinical diagnosis of RLS ( $p=0.04)$ (Figure).

Table 2 lists the epidemiological characteristics and the average score of the scales of daytime sleepiness assessed on regular individuals and individuals with RLS. Among these we can emphasize that the age of patients with RLS was significantly lower than patients without RLS $(p=0.02)$ (Table 2).

\section{DISCUSSION}

Despite the negative impact on the quality of life of individuals, RLS is considered a highly under diagnosed disease and its symptoms are often justified by associated diseases ${ }^{13-15}$. Thus, this study sought to establish the prevalence of the idiopathic form of this disease in a selective group of individuals. Facing the diagnostic difficulty and the lack of diagnostic tests capable of precisely infer the presence of the disease, clinical criteria were established aiming to direct the research and facilitate the conduction of studies related to the subject. Subjects must fulfill the 4 items proposed by IRLSSG to have the diagnosis of RLS. Thus, there is no need for polysomnography except when there is suspicion of co-morbidities. Berger et al. have used successfully this method ${ }^{16}$.
Table 2. Demographic characteristics and daytime sleepiness scale scores in the 2 groups - Individuals with RLS and individuals without the syndrome.

\begin{tabular}{lcccccc}
\hline Variable & \multicolumn{3}{c}{ RLS } & & \multicolumn{2}{c}{ NS } \\
\cline { 2 - 3 } \cline { 5 - 6 } \cline { 5 - 6 }$\quad$ Sex & $\%$ & $\mathrm{n}$ & & $\%$ & $\mathrm{n}$ \\
\hline Male & 62.5 & 5 & & 30.0 & 21 \\
Age & 37.5 & 3 & & 70.0 & 49 \\
BMI & 38.7 years* & & 47.4 years \\
Obesity & $21.8 \mathrm{~kg} / \mathrm{m}^{2}$ & & $25.3 \mathrm{~kg} / \mathrm{m}^{2}$ \\
Smoking & 0.0 & 0 & & 12.8 & 9 \\
Quit smoking & 0.0 & 0 & & 4.3 & 3 \\
Epworth AS & 25.0 & 2 & & 11.4 & 8 \\
Stanford AS & \multicolumn{2}{c}{9.9 points } & & \multicolumn{2}{c}{7.6 points } \\
\hline
\end{tabular}

RLS: Individuals with clinical diagnosis of RLS; NS: Individuals without RLS; BMI: Body mass index (obtained by dividing body weight in kilograms by the square of height in meters); Obesity was defined as $\mathrm{BMI} \geq 30 \mathrm{~kg}$ / $\mathrm{m}^{2}$; AS: Average score; *Statistic significance by $t$-student test $(\mathrm{p}<0.05)$.

In our study we found prevalence similar to that found in literature, $10.25 \%$ of patients met the diagnostic criteria and $14.1 \%$ had related symptoms. Other studies have reported prevalence from 2.5 to $15 \%$ and it is highly variable depending on the age and design addressed ${ }^{17-19}$. Rothdach et al. conducted a study using the same diagnostic criteria and showed a prevalence similar to the one found in our sample, $9.8 \%{ }^{4}$. Despite being a disease of elderly it may arise between 27 and 41 years. Several authors provide data showing an increased prevalence in elderly. This confronts our results which indicate a significantly lower mean age in individuals with $\mathrm{RLS}^{20}$. Some conditions, such as anemia, pregnancy and chronic renal failure, are associated with increased prevalence, reaching rates up to 25 and $30 \%$ 21,22.

Even though our sample is mostly composed of male subjects ( 52 males vs. 26 female), we observed that the majority of individuals with RLS were females (62.5\% / $\mathrm{p}=0.07)$. The prevalence of the syndrome among women of this sample was $19.23 \%$. Data in the literature confirm higher incidence among females. Berger et al. demonstrated higher prevalence in women, but their results showed that nulliparous women had similar prevalence compared to males and that the number of pregnancies was associated with increased risk of being the bearer of RLS. The reason for this deterioration is related to the changes in the secretion of sex hormones during pregnancy (16). Regarding the male population, the prevalence of RLS was $5.76 \%$. This rate is similar to the one shown by Rothdach ${ }^{4}$ and Ulfberg $^{23}$. The latter author conducted a study with an exclusively male population and the prevalence of RLS was $5.8 \%$. 
In addition to age, obesity has also been reported as a possible risk factor for RLS. The explanation could be related to the greater likelihood of co-morbidity development in obese patients ${ }^{17}$. In our study, all patients considered obese $(\mathrm{BMI} \geq 30)$ belonged to the group not carrying the syndrome, which does not strengthen this hypothesis. Smoking was suggested as another possible risk factor. In the group of patients with RLS, $25 \%$ of individuals had quitted smoking, but none reported active smoking. These correlations were not yet substantially proven by the studies evaluated, but it is recommended do not smoke at night because smoking can worse the RLS symptoms ${ }^{16,17}$.

The intensity of periodic movements of the legs caused by the RLS varies according to the circadian rhythm. Episodes occur mainly in the first half of the night, non-REM sleep stage 1 or 2, leading to arousals, sleep fragmentation, non-reparative sleep and daytime sleepiness ${ }^{3,24,25}$. Excessive daytime sleepiness can be associated to obstructive sleep apnea syndrome (OSAS), which can be a cause of $\mathrm{RLS}^{26-28}$. We used two scales to measure the presence of daytime sleepiness in our sample. The results of the questionnaire of Epworth ${ }^{7}$ showed a significant association between the presence of RLS and daytime sleepiness. The scores in the Stanford scale ${ }^{8}$ were higher in patients with RLS, despite the slight variation between the two groups, only 0.5 points. The sleep disorders account for $26.2 \%$ of consultations of patients with RLS, so it is of great importance that this correlation is made during the clinical investigation ${ }^{29}$.

The questionnaire of severity developed by IRLSSG ${ }^{12}$ was used to individuals with RLS, checking the severity, frequency and impact on daily life caused by symptoms. The average score of patients suffering from RLS was 10.75 points. McManama et al. showed that the imposition of a physical activity program, seeking better conditioning provided a significant reduction in the severity of symptoms in only six weeks of training ${ }^{30}$. But, it is valid to emphasize that physical exercise during the hour prior to sleeping has been correlated to increased risk of developing RLS ${ }^{29}$.

The drug treatment of the disease also showed good results in reducing the severity of symptoms. The American Academy of Sleep Medicine considers dopaminergic agents gold standard for the treatment of RLS. The first drug used was the L-Dopa, but it was left aside due to many side effects. Pramipexole is an effective drug in most cases and is being widely used. In addition to drug treatment and behavioral modifications, it is important to identify and treat the co-morbidities associated with the disease ${ }^{6,31}$.

In conclusion, RLS is quite prevalent in our population especially in young adults. Although we have not found statistical significance regarding gender (we believe that a larger sample could show the syndrome's association with the female sex). We suggest that the presence of drowsi- ness and daytime sleepiness should always be investigated as they are a marker to RLS. Potential risk factors to the development of the syndrome such as advanced age, obesity and smoking have not been confirmed by our results; nonetheless our sample consisted of a selective group of individuals.

\section{REFERENCES}

1. Ekbom KA. Restless legs. Acta Med Scand 1945;158(Suppl):S4-S124

2. Walters AS. Toward a better definition of the restless legs syndrome: the International Restless Legs Syndrome Study Group. Mov Disord 1995; 10:634-642.

3. Trenkwalder C, Walters AS, Hening W. Periodic limbs movements and restless legs syndrome. Neurol Clin 1996;14:629-650.

4. Rothdach AJ, Trenkwalder C, Haberstok J, Keil U,Berger K. Prevalence and risk factors of RLS in elderly population. Neurology 2000;54: 1064-1068.

5. The 2001 Sleep in America Poll. Washington (DC): National Sleep Foundation, 2001.

6. Chokrovertry S, Jankovic J. Restless legs syndrome: a disease in search of identity. Neurology 1999;52:907-910.

7. Johns MW. A new method for measuring daytime sleepiness: The Epworth Sleepness Scale. Sleep 1992;15:376-381.

8. Hoodes E, Zarcone V, Smythe H, et al. Quantification of sleepiness: a new aprroach. Psychophysiology 1973;10:431-436.

9. Chaudhuri KR, Forbes A, Grosset DG, et al. Diagnosing restless legs syndrome (RLS) in primary care. Curr Med Res Opin 2004;20:1785-1795.

10. Chaudhuri KR. The restless legs syndrome. Time to recognize a very common movement disorder. Practical Neurol 2003;3:204-213.

11. Rutkove BR, Matheson JK, Logigian EL. Restless legs syndrome in patients with neuropathy. Muscle Nerve 1996;19:670-672.

12. The International Restless Legs Syndrome Study Group. Validation of the International Restless Legs Syndrome Study Group rating scale for restless legs syndrome. Sleep Med 2003;4:121-132.

13. Hening W, Walters AS, Allen RP, Montplaisir J, Myers A, Ferini-Strambi L. Impact, diagnosis and treatment of restless legs syndrome (RLS) in a primary care population: the REST (RLS epidemiology, symptoms, and treatment) primary care study. Sleep Med 2004;5:237-246.

14. Sevim S, Dogu O, Kaleagasi H, Aral M, Metin O,Camdeviren H. Correlation of anxiety and depression symptoms in patients with restless legs syndrome:a population based survey. J Neurol Neurosurg Psychiatry 2004;75:226-230.

15. Weimerskirch PR, Ernst ME. Newer dopamine agonists in the treatment of restless legs syndrome. Ann Pharmacother. 2001;35:627-630.

16. Berger K, Luedemann J, Trenkwalder C, John U, Kessle K. Sex and the risk of restless legs syndrome in the general population. Arch Intern Med 2004;164:196-202.

17. Phillips B, Young T, Finn L, Asher K, Hening WA, Purvis C. Epidemiology of restless legs symptoms in adults. Arch Intern Med 2000;160: 2137-2141.

18. Lavigne GJ, Montplaisir JY. Restless legs syndrome and sleep bruxism: prevalence and association among Canadians. Sleep 1994;17:739-743.

19. Högl B, Kiechl S, Willeit J, et al. Restless legs syndrome. A communitybased study of prevalence, severity, and risk factors. Neurology 2005;64: 1920-1924.

20. Allen RP, Earley CJ. Restless legs syndrome: a review of clinical and pathophysiologic features. J Clin Neurophysiol 2001;18:128-147.

21. Lee KA, Zaffke ME, Baratte-Beebe K. Restless legs syndrome and sleep disturbance during pregnancy: the role of folate and iron. J Womens Health Gend Based Med 2001;10:335-341.

22. Manconi M, Ferini-Strambi L. Restless legs syndrome among pregnant women. Sleep 2004;27:350.

23. Ulfberg J, Nystrom B, Carter N, Edling C. Prevalence of restless legs syndrome among men aged 18 to 64 years: an association with somatic disease and neuropsychiatric symptoms. Mov Disord 2001;16:1159-1163.

24. Culebras A. Restless legs syndrome and periodic limb movements of 
sleep. In: Antonio Culebras (Ed). Clinical Handbook of sleep disorders. Boston: Butterworth-Heinemann, 1996:251-256.

25. Montplaisir J, Nicolas A, Godbout R, Walters A. Restless legs syndrome and periodic limb movement disorder. In: Krigger MH, Roth T, Dement WC (Eds). Principles and practice of sleep medicine, $3^{\text {rd }}$ Ed. W.B. Saunders, 2000:742-752.

26. American Sleep Disorders Association. The International Classification of sleep disorders. Rochester, Minn, USA 2005.

27. Kripke DF, Ancoli-Israel S, Okudaira N. Sleep apnea and nocturnal myoclonus in the elderly. Neurobiol Aging 1982;3:329-336.

28. Reynold CF, Coble PA, Spiker DG, Neil JF, Holzer BC, Kupfer DJ. Preva- lence of sleep apnea and nocturnal myoclonus in major affective disorders: clinical and polysomnographic findings. J Nerv Ment Dis 1982;170: 565-567.

29. Ohayon MM, Roth T. Prevalence of restless legs syndrome and periodic limb movement disorder in the general population. J Psychosom Res 2002;53:547-554.

30. Aukerman MM, Aukerman D, Bayard M, Tudiver F, Thorp L, Baile B. Exercise and restless legs syndrome: a randomized controlled trial. JABFM 2006;19:478-486.

31. Zucconi M, Oldani A, Castronovo C, Ferini-Strambi L. Cabergoline is an effective single-drug treatment for restless legs syndrome: clinical and actigraphic evaluation. Sleep 2003; 26:815-818. 